Disponível em:

http://editora.unoesc.edu.br/index.php/race

RACE, Joaçaba, p. 105-130, Edição Especial, 2017

\title{
AVALIAÇÃO DE POLÍTICAS PÚBLICAS COMO INDUTORA DE APRENDIZAGEM: PERCEPÇÃO DE GESTORES ESTADUAIS DO PROGRAMA BOLSA FAMÍLIA
}

Public policies evaluation as inductive learning: perception of state managers on the Programa Bolsa Família

Doraliza Auxiliadora Abranches Monteiro

E-mail: doraliza_monteiro@yahoo.com.br Doutora em Administração pela Universidade Federal da Bahia; Mestre em Administração pela Universidade Federal de Viçosa; Professora no Centro de Artes, Humanidades e Letras da Universidade Federal do Recôncavo da Bahia. Endereço para contato: Rua Mestro Irineu Sacramento, s/n, Centro, 44300-000, Cachoeira, Bahia, Brasil.

\section{Elizabeth Matos Ribeiro}

E-mail: ematosribeiro@gmail.com

Doutora em Ciências Políticas e da Administração pela Universidade de Santiago de Compostela, Espanha; Graduada em História pela Universidade Federal da Bahia; Professora Associada na Escola de Administração da Universidade Federal da Bahia.

Artigo recebido em 26 de junho de 2017. Aceito em 13 de novembro de 2017. 
Resumo

No presente estudo objetivou-se analisar como as práticas avaliativas implementadas pelo Ministério do Desenvolvimento Social e Combate à Fome (MDS) para o Programa Bolsa Família (PBF) têm proporcionado processos de aprendizagens nas práticas de gestão do Programa junto a governos estaduais. Optou-se pela coleta de dados por meio de questionário semiestruturado, que foi aplicado a gestores estaduais do PBF por meio eletrônico (Google Forms). Foram investigados aspectos do perfil pessoal e profissional dos gestores, bem como questões relacionadas aos processos de aprendizagens resultantes das pesquisas de avaliação do PBF. Os principais achados da pesquisa permitem inferir que os processos de aprendizagem resultantes das pesquisas avaliativas do MDS para o PBF junto aos estados foram baixos, e que a percepção de aprendizado está mais relacionada aos aspectos gerenciais (vinculados à execução do PBF) do que a aspectos mais instrumentais e conceituais que possibilitem a esses atores assumirem um papel mais ativo e autônomo junto à gestão do Programa.

Palavras-chave: Avaliação de políticas públicas. Aprendizagem organizacional. Programa Bolsa Família.

\begin{abstract}
The purpose of this study was to analyze how assessment practices, implemented by the MSD for the Programa Bolsa Família (PBF), have provided for the learning processes in the management practices and/or progam management as the government state. We chose to collect data through a semi-structured questionnaire, which were applied to state managers of the PBF through electronic media by Google Forms. We investigated aspects of the personal and professional profile of the managers, as well as questions related to the learning processes resulting from the PBF evaluation research. The main findings from this study allow the researcher to infer that the learning processes resulting from evaluative research of MSD for $P B F$ with the states were very low. It was also observed that the perception of learning is more related to managerial aspects (linked to the executation of the PBF) rather than to instrumental and conceptual factors - wich would allow these managers to assume more active roles, and have more autonomy in the management of the Program.
\end{abstract}

Keywords: Public policy evaluation. Organizational learning. Programa Bolsa Família. 


\section{INTRODUÇÃO}

A aprendizagem organizacional no setor público é um tema ainda pouco estudado e debatido, tanto no âmbito internacional quanto no cenário brasileiro. Muito já se avançou nos estudos de aprendizagem organizacional para o setor corporativo, no entanto, são poucos os estudos e pesquisadores que têm se debruçado nesse tema aplicado à dinâmica e cultura das organizações públicas, ${ }^{11}$ especialmente articulado com os conceitos e experiências advindas das práticas de avaliação de políticas públicas como instrumento relevante para a promoção de novas aprendizagens organizacionais.

Calmon, em um importante estudo realizado na década de 1990, buscou contribuir para o entendimento da dinâmica do processo de aprendizagem organizacional no setor público brasileiro, verificando de que maneira a avaliação de programas tem sido utilizada como instrumento capaz de estimular esse processo. Os resultados apontaram que as práticas avaliativas representaram um importante instrumento de feedback para os processos de aprendizagem organizacional. No entanto, constatou-se que esse aprendizado poderia ter sido mais efetivo.

Outro estudo relevante foi realizado por Guimarães et al. (2003) com o objetivo de investigar em que medida o Ministério da Integração Nacional se caracterizava como uma organização de aprendizagem. Nesse trabalho foi discutido não apenas o campo da aprendizagem nas organizações, mas também suas características e, particularmente, suas relações com inovação e mudanças organizacionais. Os resultados do referido estudo mostram que na organização estudada, apesar de apresentar algumas características que favoreceram o processo de aprendizagem, esta ainda não se tornou uma prática institucionalizada.

Carmo e Oliveira (2009), com o objetivo de descrever o processo de aprendizagem organizacional em municípios do Estado de Minas Gerais, buscaram identificar em que medida ocorre a capacitação de pessoas, a socialização e a institucionalização do conhecimento no setor público mineiro. Com base nos resultados do estudo,

\footnotetext{
${ }^{1}$ Estudos realizados por Soares Neto (2010) mostraram que em um levantamento de 2.143 artigos em quatro prestigiadas revistas acadêmicas nacionais e em uma publicação de encontro acadêmico nacional, revelou que apenas 24 artigos abordavam a temática da aprendizagem organizacional no setor público brasileiro, representando 0,01\% das publicações consideradas. O autor optou pelo cômputo de periódicos de alto impacto, qualificados pela CAPES, com acessibilidade ao leitor interessado. Na mesma direção, pesquisadores internacionais como Rashman,Withers e Hartley (2009) enfatizam também que a aprendizagem organizacional é pouco pesquisada no setor público.
} 
pode-se reconhecer que as prefeituras estudadas apresentaram características próprias às “organizações que aprendem”, havendo espaço para a diversidade e a autonomia, embora o estudo tenha indicado também que existem diversos aspectos culturais que dificultam avançar no processo de aprendizagem.

Como o ambiente das organizações é dinâmico, especialmente as públicas, em que emergem sempre novas e complexas situações, a aprendizagem organizacional ganha relevância por sua capacidade de detectar falhas e corrigir, mudar normas, regras, políticas e objetivos que as causaram.

Precursores dos estudos de aprendizagem organizacional, como Argyris e Schön (1978), explicam esse fenômeno como um "processo pelo qual os membros organizacionais detectam erros ou anomalias e os corrigem ao reestruturar as teorias ou metodologias em uso na organização.” Com base nessa definição, Carmo e Oliveira (2009) afirmam que a aprendizagem organizacional é resultado da prática de compartilhamento, socialização e institucionalização do conhecimento que se situam, portanto, no contexto organizacional como etapas de um processo contínuo que ocorre no meio de grupos, coletividade ou comunidade de integrantes.

Permeado por essas reflexões, no presente estudo teve-se como objetivo analisar como as práticas avaliativas, implementadas pelo Ministério do Desenvolvimento Social e Combate à Fome (MDS) para o Programa Bolsa Família têm proporcionado processos de aprendizagens nas práticas de gestão do Programa junto a governos estaduais e Burocratas de Médio Escalão (BMEs). ${ }^{2}$

O artigo está estruturado em seis seções, sendo a primeira a introdução, em que já foi apresentada a proposta do estudo. Na segunda visou-se descrever os aspectos teóricos relacionados à avaliação de políticas públicas como instrumento de aprendizagem organizacional no setor público; a terceira é uma breve discussão acerca do Programa Bolsa Família e da institucionalização da função avaliação. Na quarta apresenta-se a descrição dos procedimentos metodológicos com ênfase nas características socioeconômicas dos estados participantes e na abordagem dos métodos de tratamento e análise dos dados. Na quinta há a apresentação dos resultados, ressaltando o perfil pessoal e profissional dos gestores e os processos de aprendizagens organizacionais resultantes das pesquisas de avaliação. Por fim, na última, as considerações finais.

\footnotetext{
${ }^{2}$ Entende-se por Burocratas de Médio Escalão (BMEs) atores que desempenham função de gestão e direção intermediária (como gerentes, diretores, coordenadores ou supervisores) em burocracias públicas e privadas (LOTTA; PIRES; OLIVEIRA, 2014).
} 


\section{AVALIAÇÃO DE POLÍTICAS PÚBLICAS COMO INSTRUMENTO DE APRENDIZAGEM ORGANIZACIONAL NO SETOR PÚBLICO}

Para Calmon (1999), a aquisição de conhecimento no âmbito da organização ocorre a partir de um processo de feedback no qual se percebem, monitoram e examinam, continuamente, informações relevantes advindas dos ambientes interno e externo. Desse modo, ao considerar a avaliação como uma das formas pelas quais uma organização pode adquirir conhecimento, a autora enfatiza a importância de se estabelecer uma conexão positiva entre avaliação e aprendizagem organizacional.

Tomando como referência a definição de Thoenig (2000), aprendizagem significa um processo contínuo e orgânico no qual a avaliação pode oferecer ensinamentos decisivos e não ser vista apenas como uma operação conduzida ocasionalmente, mas se tornar parte de um processo mais amplo do pensar e fazer administrativo. Para o autor, a avaliação pode atuar, portanto, como uma ferramenta importante para o aprendizado, auxiliando governos e cidadãos a formarem pontos de vista embasados, garantindo a tomada de decisões com base em informações seguras e conscientes das ações a serem assumidas. Essa afirmação se fundamenta, pois, em uma visão crítica da operacionalização de ações administrativas como tarefas primordiais a perseguir, o que implica a necessidade de certa maturidade, sofisticação e percepção para utilizar bem as informações trazidas pelos instrumentos de avaliação.

Nesse sentido, conforme ressaltam Guimarães et al. (2003), o processo de aprendizagem em uma organização envolve um conjunto de etapas que se inicia na identificação dos conhecimentos que esta necessita, assim como no desenvolvimento ou aquisição desses conhecimentos, na sua estruturação, disseminação, uso e incorporação no processo produtivo, com a finalidade de aumentar o seu nível de competitividade.

Outro elemento relevante para a análise é trazido por Schneider (1986), que aponta que, nas décadas de 1970 e 1980, havia dois problemas interdependentes para a utilização da avaliação como instrumento de aprendizagem. O primeiro problema estava vinculado ao fato de que as avaliações realizadas naquele contexto eram irrelevantes para as decisões que os deliberadores tinham que tomar. O segundo era que os tomadores de decisão sentiam falta de certas informações que raramente eram produzidas pelos estudos de avaliação realizados. Para o autor, os dois problemas destacados possuíam a mesma origem: o esquema conceitual que orientava a avaliação não dava atenção suficiente aos sistemas de tomada de decisão a quem devia servir. Em síntese, pode-se afirmar que faltava às concepções e aos instrumentos de avalia- 
ção, naquele contexto, responder às seguintes perguntas: qual sua finalidade? Por que e para que (e quem) se está avaliando? Desejava-se aprender e/ou apreender algo com esses instrumentos avaliativos?

Como base nessas provocações, no presente estudo entende-se que a decisão de construir instrumentos de avaliação de políticas públicas envolve a busca da identificação dos conhecimentos que a organização necessita desenvolver ou levantar. A execução da avaliação deve ser definida, portanto, tomando como base seu processo de estruturação, assim como os resultados que se deseja alcançar e a utilização destes no aprimoramento ou modificação das políticas avaliadas, integrando, desse modo, as etapas disseminação, uso e incorporação no processo de trabalho.

Assim, concorda-se com a definição de Boullosa (2009), que afirma que avaliação é um processo de construção de significados ou de significâncias, em que cada sujeito avaliador ou avaliado (diferentes atores com múltiplas realidades) deve enfrentar um problema semântico relacionado à compreensão do significado da avaliação e dos seus processos. Entende-se, dessa forma, que a avaliação produz constantemente processos de aprendizagem, e esses movimentos de mudanças em recursos organizacionais (pessoas, máquinas, dinheiro, conhecimentos, tecnologias, etc.) interagem com a finalidade de alterar atitudes, comportamentos e valores organizacionais, visando, por meio de uma compreensão mais ampla da realidade, aperfeiçoar as ações administrativas da organização, conforme corroboram Guimarães et al. (2003).

Thoenig (2000) reforça essa análise ao destacar que a avaliação ensina uma lição otimista por meio do que denomina princípio do conhecimento utilizável ou aprendizagem cumulativa para definir o papel relevante das ações de avaliação.

Com base nessas definições críticas, neste artigo, entende-se que a avaliação altera, progressivamente, a compreensão do seu objeto/sujeito, assim como da sua própria finalidade ou objetivo.

Escolar e Domench (2002), ao discorrerem sobre a experiência avaliativa da Argentina, enfatizam que esta contribui para ajustar certas linhas de trabalho (do Poder Público), citando como exemplos os indicadores de monitoramento e avaliação utilizados, o modelo de gestão, os instrumentos de identificação de beneficiários e outros tipos de atividades financiadas pelo programa ou política.

Outro aspecto importante destacado por Faria (2005) é o de que outros usuários, além daqueles envolvidos diretamente nos programas em questão, podem se valer das descobertas ou de outros elementos advindos do processo avaliativo, destacando os seguintes: gerentes de programas similares e/ou de diferentes níveis governamentais; agentes do governo central e representantes de fundações, interessados em 
conhecer projetos exitosos que mereçam financiamento ou preocupados em melhorar os programas dos quais são responsáveis; membros do legislativo interessados na melhoria de programas existentes ou na elaboração de novas propostas; e cientistas sociais e outros avaliadores que buscam aprender com as descobertas e com as metodologias empregadas.

Nessa mesma direção, Weiss (1998) sugere a existência de dois usuários potenciais das avaliações: as próprias organizações que administram o Programa avaliado ou programas similares e o público em geral ou a sociedade civil. Para os objetivos e propósitos com este estudo foi dada ênfase ao processo de aprendizagem organizacional destacado pelo autor ao considerar que deve ser feito não apenas o contraponto à tradicional ênfase da aprendizagem no indivíduo como usuário, mas também deve ser mencionada a importância que tem sido dada atualmente à questão da learning organization - "organização que aprende" - e aos limites, tradições e procedimentos cristalizados e/ou impostos pelas organizações.

Por fim, cabe destacar que existem fatores que podem interferir na utilização dos resultados da avaliação como instrumento de aprendizagem, conforme destaca Weiss (1998): a existência de crenças e interesses conflitantes na organização que gerencia o Programa; a ocorrência de conflitos de interesses entre as distintas unidades do Programa; as mudanças no pessoal encarregado; a eventual inflexibilidade das regras e dos padrões operacionais da organização encarregada, que podem impedir a adoção das recomendações feitas quando da avaliação; e as mudanças nas condições externas, como cortes orçamentários e alterações no ambiente político. Todos esses fatores podem tornar impossível para a organização responder à necessidade de mudança revelada pelos avaliadores. Conforme ratificam Carmo e Oliveira (2009), esses fatores podem privar ou dificultar o processo de aprendizagem, já que aprendizado e mudanças são aspectos estreitamente relacionados, na medida em que a aprendizagem desponta de um processo de alteração permanente no comportamento dos indivíduos e grupos, sendo resultante, portanto, das práticas, dos processos educativos e do treinamento.

Pela síntese teórica aqui exposta, é possível identificar que existe uma relação estreita e consequente entre avaliação de políticas públicas, como potencial instrumento indutor de aprendizagem organizacional. 


\section{PROGRAMA BOLSA FAMÍLIA E INSTITUCIONALIZAÇÃO DA FUNÇÃO AVALIAÇÃO NO MDS}

O Programa em análise emerge em um contexto socioeconômico mais amplo, marcado pelo aprofundamento da miséria, da pobreza e do aumento vertiginoso da desigualdade social no mundo, fenômeno que se manifesta nos países capitalistas desenvolvidos, bem como assume efeitos ainda mais perversos nas nações consideradas subdesenvolvidas e em desenvolvimento, que, além de refletirem as consequências negativas advindas de um ambiente econômico permeado por um alto nível de desemprego e baixo rendimento proveniente do trabalho, têm que enfrentar os problemas advindos do crescimento da violência e da criminalidade.

Dessa maneira, os padrões de gestão que têm orientado tal política no Brasil possuem como base a descentralização financeira, administrativa e técnica, compartilhada pela União, Estados, Distrito Federal e Municípios. Segundo os padrões federativos que orientam o ordenamento jurídico brasileiro, os três Entes Federados deverão trabalhar em conjunto, de forma integrada, para aperfeiçoar, ampliar e fiscalizar a execução do PBF. Apesar de União e Estados terem papel relevante nesse arranjo institucional, a Constituição Federal preservou um espaço de maior destaque para os municípios, por serem os Entes mais próximos dos cidadãos. Aos municípios cabe, portanto, a responsabilidade direta pela gestão e gerência do Programa, tendo nos instrumentos de acompanhamento e avaliação das famílias e atendimento das condicionalidades fundamentais (políticas de saúde e educação) a base fundamental de gestão da política e as bases do investimento em capital humano. Em síntese, a concepção e implantação, enquanto Política Nacional de Transferência de Renda, é de compartilhamento de responsabilidades entre a União, Estados e Municípios, caracterizando-a como uma política multifederativa.

No contexto da institucionalização do MDS, como instância de promoção da política de desenvolvimento social brasileiro, cabe destacar também a importância da criação da Secretaria de Avaliação e Gestão da Informação (SAGI), responsável pelo monitoramento e avaliação no MDS. Autores como Thoenig (2000), Escolar e Domench (2002) e Faria (2005) têm discorrido sobre a importância de institucionalização da função avaliação na gestão governamental, isso porque esse instrumento permite fornecer elementos relevantes para o (re) desenho de novas intervenções ou para o aprimoramento de políticas e programas em curso. Nesse sentido, diversos autores têm avaliado positivamente a criação do MDS, considerando, inclusive, que a gestão de políticas públicas tem avançado consideravelmente com a criação da SAGI, órgão 
específico de avaliação e geração de informações das políticas sociais dirigidas pelo MDS (NASCIMENTO, 2006; BOULLOSA, 2009; NOGUEIRA; CAVALCANTE, 2009; DULCI, 2010).

Para muitos pesquisadores, os instrumentos de avaliação criados e utilizados pelo MDS como parte do eixo da política de inclusão foram os que mais avançaram no Brasil e têm contribuído muito para o aperfeiçoamento da gestão governamental, particularmente no que se refere aos mecanismos de avaliação de programas sociais.

Como afirmam Vaitsman, Rodrigues e Paes-Sousa (2006) e Boullosa (2009), a criação de uma unidade horizontal dentro de uma estrutura ministerial para o monitoramento e avaliação das políticas e programas de proteção e assistência social representa um elemento de inovação importante na prática de gestão pública em vários sentidos. Esses autores asseguram que a incorporação das práticas de monitoramento e avaliação tem permitido à gestão pública federal inovar no processo de tomada de decisões, além de agregar qualidade às práticas administrativas, contribuindo, pois, para o desempenho dos programas por meio do uso na relevante base de informação e análise de dados disponíveis. Essas medidas gestoriais e gerenciais têm potencial para o fortalecimento da expansão de uma cultura de transparência e accountability na administração pública, por meio da publicização de indicadores de monitoramento, publicação de resultados de estudos de avaliação e disponibilização à comunidade científica dos microdados das pesquisas.

Na próxima seção é descrito o percurso metodológico adotado para o alcance dos objetivos propostos neste artigo.

\section{PROCEDIMENTOS METODOLÓGICOS}

A pesquisa tem um caráter exploratório e descritivo, de natureza predominantemente qualitativa, com o enfoque na análise de aprendizagem em avaliações junto às esferas subnacionais estaduais responsáveis pela gestão do Programa Bolsa Família.

Para o tratamento e a análise dos dados, utilizou-se de estatística descritiva e análise de conteúdo. Predominou a análise de frequência, medidas de tendência central e dispersão como média, desvio padrão e assimetria, que visam verificar como os dados estão distribuídos e concentrados. A análise de conteúdo visou "compreender criticamente o sentido das comunicações, seu conteúdo, as significações explícitas ou ocultas” (MOZZATO; GRZYBOVSKI, 2011) emitidas pelos gestores do Programa em estudo. 
Foram cinco os gestores estaduais do PBF que participaram da pesquisa. Para qualificar essa participação, destaca-se que os estados participantes do estudo possuem, em sua totalidade, 24,3\% dos beneficiários do PBF e absorveram 24\% dos recursos totais destinados a esse Programa em 2014 (MINISTÉRIO DO DESENVOLVIMENTO SOCIAL E COMBATE À FOME, 2015).

Com o objetivo de preservar a identidade dos gestores, foi acordado que não seriam divulgados seu nome, bem como a identificação do estado participante da pesquisa, visto que seria possível reconhecer o gestor estadual pela identificação da subunidade nacional entrevistada, porém algumas características socioeconômicas dos estados foram expostas. Por essas razões, optou-se por caracterizar os estados pela seguinte referência: GE-A, GE-B, GE-C, GE-D e GE-E, conforme representado no Esquema a seguir:

Esquema 1 - Gestores estaduais participantes do estudo

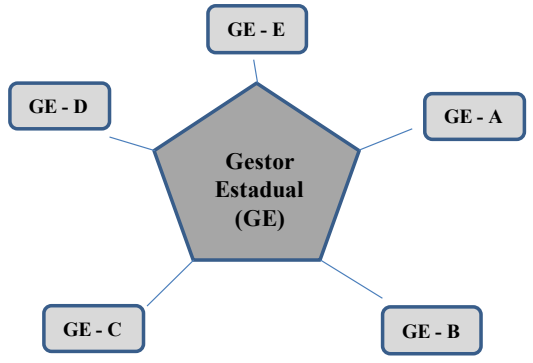

Fonte: os autores.

O Quadro 1 possui algumas informações dos estados participantes no intuito de conhecer as principais características socioeconômicas da região.

Quadro 1 - Características socioeconômicas dos estados participantes da pesquisa

\begin{tabular}{|l|l|}
\hline \multicolumn{1}{|c|}{ Estados } & \multicolumn{1}{c|}{ Características } \\
\hline Estado A & $\begin{array}{l}\text { Possui o maior número de beneficiários e absorve a maior percentagem dos re- } \\
\text { cursos do Programa. Os fatores determinantes dessa alocação estão relacionados } \\
\text { à alta população, à presença de alta concentração de renda, às altas taxas de anal- } \\
\text { fabetismo e mortalidade infantil, à baixa expectativa de vida em relação a outros } \\
\text { estados e a outras vulnerabilidades. }\end{array}$ \\
\hline Estado B & $\begin{array}{l}\text { Está entre os 10 em número de beneficiários e absorção dos recursos do Programa. } \\
\text { Está situado na região mais rica do País, por abrigar uma economia forte e diversi- } \\
\text { ficada, e também a região mais populosa, marcada pelo processo de urbanização, } \\
\text { em que merece destaque a migração de pessoas com baixo nível de escolaridade e } \\
\text { desempregadas para essa região, o que contribui para a marginalidade, favelização, } \\
\text { crescimento das taxas de desemprego, subemprego e informalidade, entre outros. }\end{array}$ \\
\hline
\end{tabular}




\begin{tabular}{|l|l|}
\hline Estado C & $\begin{array}{l}\text { Possui baixa população, assim como uma fraca economia perante os outros esta- } \\
\text { dos brasileiros e os contemplados na pesquisa. Taxas ruins de esperança de vida, } \\
\text { de analfabetismo e mortalidade infantil, IDH considerado médio. }\end{array}$ \\
\hline Estado D & $\begin{array}{l}\text { Um dos menores estados em população e extensão territorial. Com uma das sete } \\
\text { economias mais fracas, possui piores taxas de esperança de vida, altas taxas de } \\
\text { mortalidade infantil e analfabetismo. }\end{array}$ \\
\hline Estado E & $\begin{array}{l}\text { Localizado em uma grande região com forte economia, é um dos cinco menores es- } \\
\text { tados do Brasil, porém com grande população se comparado ao seu território. Possui } \\
\text { boa esperança de vida e alto IDH, assim como baixas taxas de mortalidade infantil e } \\
\text { analfabetismo, em relação a outros estados com características parecidas. }\end{array}$ \\
\hline Fonte: adaptado do IBGE (2015).
\end{tabular}

Os questionários foram destinados aos gestores estaduais do PBF por meio eletrônico (Google Forms) no período de janeiro de 2015. O questionário continha, na primeira parte, o perfil pessoal e profissional dos gestores e, na segunda, aspectos sobre aprendizagens resultantes das pesquisas de avaliação do PBF, na percepção dos gestores, por meio das questões de livre resposta dada, conforme exposto nos resultados e discussão do estudo.

\section{RESULTADOS E DISCUSSÃO}

Inicialmente é descrito o perfil pessoal e profissional dos gestores respondentes que contemplam os seguintes aspectos: gênero, idade, grau de instrução formal, cargos que ocupam no governo do Estado, principais funções desempenhadas, tempo de experiência profissional, tempo de experiência com o PBF, bem como carga horária de trabalho, tipo de vínculo empregatício e remuneração.

E, por fim, são expostas questões relacionadas aos processos de aprendizagem resultantes das pesquisas de avaliação do $P B F$, com base na percepção dos gestores, diante das questões de livre resposta expostas no questionário e descritas ao longo dos resultados.

\subsection{PERFIL PESSOAL E PROFISSIONAL DOS GESTORES ESTADUAIS}

Todos os gestores estaduais participantes da pesquisa são mulheres, e o grau de instrução formal predominante é nível superior com investimento em formação em pós-graduação (em nível de especialização e mestrado). Nesse aspecto, três gestoras confirmaram ter nível superior e de pós-graduação, o que para os objetivos da pesqui- 
sa é avaliado como indicador positivo, especialmente em se tratando da importância da capacidade técnica para a gestão do PBF nos estados. É possível reconhecer, com base nessas informações, o bom nível de formação desses profissionais, revelando o esforço das subunidades em contratar/selecionar quadros qualificados. Outro elemento que chamou a atenção na análise do perfil profissional foi o fato de que, entre as gestoras participantes, há predominância de formação em Serviço Social, Gestão Pública e Comunicação Social, áreas que refletem uma grande aderência às atribuições exigidas para o PBF, especialmente as áreas de Serviço Social e Gestão Pública.

No que se refere às titulações em nível de pós-graduação, constatou-se também significativa aderência ao campo de formação e atuação da Assistência Social. Nesse quesito, observou-se que uma gestora possui nível de mestrado em Comunicação e Culturas Contemporâneas e também tem especialização na mesma área com ênfase em Relações Públicas. Há outra gestora que tem dois títulos de especialização.

Quando perguntadas sobre o cargo que ocupam na coordenação estadual do PBF todas responderam que têm a função de Coordenadoras Estaduais do PBF e Cadastro Único. A confirmação da função e atribuições de coordenação do Programa ganha relevância para a análise do perfil das entrevistadas em razão do fato de representar a percepção clara dessas gestoras sobre o seu papel e atribuições na gestão do Programa no âmbito do estado, o que poderia contribuir, sobremaneira, para o processo de aprendizagem dos gestores municipais, visto que esta é uma das atribuições constitucionais dos estados junto às municipalidades - isto é, os Entes Estaduais têm entre suas atribuições mais relevantes monitorar e capacitar os gestores municipais para que esses entes alcancem o nível de excelência e qualidade na prestação dos serviços de Assistência Social nos territórios (BRASIL, 1988).

Quando questionadas sobre a principal atividade desempenhada na coordenação, todas as gestoras apontam para as principais funções que competem aos coordenadores estaduais do Programa, que são as seguintes: monitorar e orientar os municípios para melhorar a gestão do PBF e promover a articulação de programas complementares no estado. Essa descrição confirma, portanto, a afirmação feita no parágrafo anterior ao destacar as competências que cabem a cada subunidade federativa com base na CF de 1988.

Outro dado relevante revelado pela pesquisa em relação ao perfil dos gestores estaduais é a confirmação da fragilidade do tipo de vínculo empregatício estabelecido com o Estado. Nesse aspecto, duas gestoras declararam ocupar cargos de provimento em comissão sem vínculo estável, e duas declararam ser do quadro efetivo do estado - ou seja, são concursadas. Foi ressaltado também que uma do quadro efetivo 
(concursada) foi deslocada para assumir cargo de confiança. No universo da pesquisa, dos cinco estados selecionados, três gestoras são efetivas, o que analisado de forma isolada poderia ser considerado um dado positivo. Entretanto, como declarado pelas coordenadoras, existe no quadro técnico da secretaria alto número de profissionais contratados.

Esses resultados reforçam uma discussão ainda não superada no Brasil, especialmente no âmbito da gestão estadual e municipal, que é o excesso de técnicos (gestores, coordenadores ou trabalhadores) sem vínculo efetivo e estável com os governos. As consequências dessa realidade têm sérias implicações no papel das políticas públicas como indutor de aprendizagem, na medida em que a alta rotatividade e os vínculos políticos (poder local) impedem que haja a formação de capital técnico e se faça a gestão do conhecimento nas organizações públicas estaduais e municipais.

Em relação ao perfil de idade das gestoras estaduais avaliadas, a idade média é de 43 anos, porém uma gestora tem idade mais baixa (24 anos). A idade ganha relevância na análise do perfil dos profissionais avaliados pelo tempo em cargos públicos e, principalmente, pela experiência prática acumulada. Nesse sentido, a profissional que tem menor idade (24 anos) revelou ter baixa experiência profissional e, portanto, pouco tempo na gestão do PBF. Mas cruzando os dados da formação com a idade baixa, pode-se pressupor que, ao já possuir nível de graduação, a referida gestora apresenta grandes possibilidades de investir no aprimoramento profissional por meio da realização de formação pós-graduada como se observou no perfil das demais gestoras com maior idade.

A média de tempo de experiência profissional das gestoras é de 8,5 anos, havendo três gestoras com maior experiência, visto que desse universo uma tem 21 anos de experiência, duas têm 8 anos e apenas duas têm de 1 a 4 anos de experiência. Quando se analisa o tempo de trabalho com o Programa, a média é de 3,7 anos, e há uma gestora no grupo com apenas 1,5 ano de experiência, assim como outra com experiência superior a 8 anos.

A média de remuneração das gestoras é de $\mathrm{R} \$ 2.960,00$. As que recebem menores salários se enquadram no grupo que declarou possuir uma carga horária de trabalho semestral de 20 a 40h, o que pode justificar, assim, os salários mais baixos em relação às outras gestoras que possuem o mesmo cargo. É relevante considerar, ainda, que cada estado avaliado possui política de cargos e salários própria, o que implica que não há um padrão nacional (ou um piso nacional) para esses profissionais. 
Tabela 1 - Variáveis descritivas que compõem o estudo

\begin{tabular}{|c|c|c|c|c|}
\hline Variáveis & Mín. & Máx. & Média & Desv. pad. \\
\hline Idade & 24 & 58 & 43 & 12,2 \\
\hline $\begin{array}{l}\text { Tempo de experiência profissional (em } \\
\text { anos) }\end{array}$ & 1,5 & 21 & 8,5 & 7,5 \\
\hline $\begin{array}{l}\text { Tempo de trabalho com o Programa } \\
\text { Bolsa Família (em anos) }\end{array}$ & 1,5 & 8 & 3,7 & 2,5 \\
\hline Remuneração média (R\$) & $1.800,00$ & $5.000,00$ & $2.960,00$ & $1.225,96$ \\
\hline $\begin{array}{l}\text { Pessoas compõem a equipe do Progra- } \\
\text { ma Bolsa Família no Estado }\end{array}$ & 2 & 12 & 7,2 & 4,2 \\
\hline População & 1.496 .880 & 16.461.173 & 8.058 .240 & 7.132 .132 \\
\hline
\end{tabular}

Em relação ao número total de pessoas que compõem a equipe do PBF dos estados avaliados, observa-se uma disparidade que, com base nas respostas dos sujeitos, pode ser atribuída a vários fatores, como tamanho dos estados, número de famílias beneficiárias, volume de recursos alocados no Programa, entre outros. No entanto, observou-se disparidade entre estados com baixo contingente de pessoas compondo a equipe (2) e outros com até 12 pessoas, mas a média é de 7,2 pessoas.

A população total dos estados selecionados possui uma média de 8.058.240 pessoas, visto que nesse universo existe estado com menor população, de 1.496.880 habitantes, e o maior supera os 16.000 .000 de habitantes, o que reflete a realidade do Brasil com a diversidade do escopo territorial e da população dos Estados e Municípios; isso implica a formação das burocracias nos governos subnacionais para o provimento de políticas públicas no Brasil.

\subsection{PROCESSOS DE APRENDIZAGENS RESULTANTES DAS PESQUISAS DE AVALIAÇÃO DO PBF}

A análise desse ponto integra quatros questões que juntas buscaram identificar quais os aspectos relacionados aos processos de aprendizagem resultantes das pesquisas de avaliação do PBF, na percepção dos gestores, conforme descrito no Quadro 2: 
Quadro 2 - Questões sobre processos de aprendizagem em avaliação do PBF

\begin{tabular}{|c|l|}
\hline 1 & $\begin{array}{l}\text { Quais as principais ações adotadas pela Secretaria, onde está alocada a coordenação estadual do } \\
\text { Programa Bolsa Família, que têm possibilitado processos de aprendizagem a partir dos resultados } \\
\text { das avaliações realizadas pelo MDS? }\end{array}$ \\
\hline 2 & $\begin{array}{l}\text { De que forma sua coordenação utiliza os resultados das pesquisas avaliativas contratadas pelo } \\
\text { MDS para o aperfeiçoamento do Programa Bolsa Família no estado? }\end{array}$ \\
\hline 3 & $\begin{array}{l}\text { Quais as principais dificuldades relacionadas ao processo de aprendizagem da coordenação do } \\
\text { Programa Bolsa Família estadual, com base nos resultados das avaliações realizadas/contratadas } \\
\text { pelo MDS e quais elementos poderiam ser melhorados nos processos avaliativos? }\end{array}$ \\
\hline 4 & $\begin{array}{l}\text { Quais as principais conquistas alcançadas por esses processos avaliativos realizados pelo MDS } \\
\text { para o Programa Bolsa Família? }\end{array}$ \\
\hline Fonte: os autores.
\end{tabular}

Fonte: os autores.

Para cada uma das questões foi realizada a análise de conteúdo das respostas, e a partir dos resultados foi apresentada e discutida cada questão, buscando refletir, desse modo, a percepção dos gestores estaduais respondentes.

Em relação às principais ações adotadas pela Secretaria, onde está alocada a coordenação estadual do PBF com vistas a possibilitar processos de aprendizagem, os resultados da pesquisa revelam o seguinte: nos Estados A e E, as gestoras declararam que suas Secretarias não adotam ações que possibilitem processos de aprendizagem; outro estado (D) declarou que não existem ações exclusivas para esse fim, informando que existe apenas a divulgação dos resultados de algumas das pesquisas realizadas pelo MDS entre as coordenações municipais e ressalta que, às vezes, essa difusão ocorre nos encontros formais do Conselho Estadual de Assistência Social (CEAS). É importante ressaltar, ainda, que a gestora do Estado E destacou a existência de déficit de servidores na gestão do Programa, alegando que esse fato prejudica o adequado funcionamento e a execução do Programa. Os gestores estaduais que declararam ações adotadas pela secretaria responsável pela gestão do PBF para esse fim, isto é, para a indução de processos de aprendizagem, destacaram que as ações que compreendem capacitações de imersão, assessoramento técnico operacional in loco e ações de monitoramento e avaliação podem ser consideradas elementos relevantes para a aprendizagem.

Em relação à utilização dos resultados das pesquisas avaliativas realizadas pelo MDS para o aperfeiçoamento do PBF nos estados, foi possível perceber, pelas respostas dos gestores, que dois estados utilizam essas informações de forma mais 
enfática, reorientando, assim, as ações do Programa no Estado. Já outros gestores avaliam que a utilização dessas informações tem sido moderada.

Cabe ressaltar que, para a maioria dos gestores avaliados, os resultados das avaliações permitem o aperfeiçoamento das ações a serem planejadas e executadas pelos estados tanto para as políticas de monitoramento quanto para as de avaliação. Nesse sentido, ressaltaram a realização de seminários nos estados e reuniões com os municípios que apresentem índices insatisfatórios na gestão do Programa (especialmente nos Estados B, C e E). Mas alguns gestores estaduais (3) destacaram, por outro lado, que as pesquisas avaliativas compõem, de maneira limitada, as orientações para qualificar e/ou capacitar as ações dos gestores, na qualidade de coordenadores do PBF. Ressaltaram, ainda, que a divulgação dos resultados das pesquisas avaliativas do MDS chega através de e-mail e mídias sociais, mas também por meio de informes passados pelas capacitações realizadas para os gestores/técnicos municipais do Programa.

Quando perguntado sobre as principais dificuldades relacionadas ao processo de aprendizagem da coordenação estadual do PBF, com base nos resultados das avaliações do MDS e também na identificação de quais elementos poderiam ser melhorados nos processos avaliativos para que contribuam de forma mais efetiva para o processo de aprendizagem, os gestores afirmaram que categorias como equipe técnica necessária à execução do Programa e infraestrutura disponibilizada nos estados são determinantes e condicionam a qualidade e os resultados da gestão do PBF. Conforme descreveu uma gestora:

[devido] A carência de equipe técnica, é praticamente inviável realizar as atividades de rotina da coordenação (a demanda é enorme) e [ainda] dar conta de se apoderar dos resultados de pesquisas avaliativas (ler, entender, compreender, questionar, contestar, concordar, trazer para a realidade e discutir com outras pessoas e setores). Tudo isso demanda tempo e dedicação, pra nossa realidade, onde a coordenação é formada por uma técnica de nível superior, e outra de nível médio em via de aposentadoria. Após 11 anos de existência do PBF e da dimensão que ele tomou, é necessário, um posicionamento do MDS sobre uma equipe mínima para gestão estadual do Programa. (GE-D) (informação verbal).

Outra declaração que apontou nessa mesma direção ressaltou que:

As principais dificuldades [da gestão estadual] são: a ausência de suporte técnico para desenvolvimento dessas pesquisas 
avaliativas para a realidade dos municípios do estado; a equipe reduzida da coordenação estadual que impossibilita aprofundar as questões estratégicas do Programa, visto que cada técnico acompanha [...] muitos municípios; a falta de capacitação para manuseio de base e banco de dados, trabalho com indicadores e realização de avaliação. (GE-A) (informação verbal).

As gestoras ressaltaram, ainda, nessa avaliação, a morosidade no andamento dos processos que comprometem a própria execução dos projetos e recursos destinados aos estados para o desenvolvimento do PBF.

Quando abordadas sobre as principais conquistas alcançadas pelos processos avaliativos realizados pelo MDS para o PBF, predominam avaliações positivas relacionadas à gestão do CadÚnico, aos avanços e ao conhecimento sobre os impactos nos indicadores relacionados ao Programa e às suas condicionalidades. Foi mencionada, também, a verificação de melhores índices na saúde, educação e assistência social, assim como a divulgação e a verificação dos resultados do Programa em longo prazo e o impacto em áreas correlatas, como educação, saúde, assistência e economia local. São destacadas também melhorias na atualização cadastral (CadÚnico), na instituição de comitês municipais intersetoriais do PBF e no aumento do número de municípios com mais cadastros realizados com visita domiciliar. Foram destacados, ainda, os "avanços no processo de avaliação e monitoramento dos programas, o que permite a correção de rotas e o constante aperfeiçoamento da gestão do mesmo.” (GE-C) (informação verbal). E, por último, outro aspecto revelado na avaliação foi que os processos avaliativos realizados pelo MDS contribuem para a desmistificação de vários mitos e preconceitos acerca do maior programa de transferência de renda do País.

\subsection{SÍNTESE DA PERCEPÇÃO DO PROCESSO DE APRENDIZAGEM ORGANIZACIONAL POR GESTOR ESTADUAL}

No Estado A, segundo as respostas da gestora, a Secretaria Estadual não adota ações que possibilitam processos de aprendizagem, a partir dos resultados das avaliações realizadas pelo MDS, contudo reconhece que há um aproveitamento dos dados e das informações obtidas pelas pesquisas avaliativas para compor as orientações dos gestores municipais, ainda que de forma limitada.

Assim, pode-se afirmar, para os objetivos desta pesquisa, que os dados obtidos são balizadores mais da esfera estadual, haja vista que a gestora apresentou um conjunto de dificuldades relacionadas ao processo de aprendizagem local, destacan- 
do, principalmente, o baixo contingente de servidores nas funções técnicas e a frágil gestão das relações entre Estado e Municípios, de modo a garantir a integração e articulação dos três entres federativos (União, Estados e Municípios) acerca de um projeto nacional dirigido para qualificar profissionais vinculados à política de inclusão socioeconômica. Em síntese, a entrevistada destacou, ainda, a falta de capacitação e a baixa experiência com a utilização de banco de dados, indicadores e dados das pesquisas disponibilizadas pelo MDS, o que permite concluir que esse conjunto de elementos impede, portanto, que o investimento que tem sido realizado pelo Ministério na área de instrumentos avaliativos do PBF carece de uma revisão de sua estratégia, especialmente se se considerar que a finalidade última do MDS é, justamente, coordenar a política nacional de Assistência Social por meio da articulação e integração dos três Entes Federativos. Aqui cabe abrir um novo questionamento para pesquisas futuras em relação a reconhecer qual a finalidade ou função das pesquisas avaliativas concebidas e desenvolvidas pelo MDS para o PBF se não é produzir um conhecimento sobre as realidades regionais e locais dos programas, de modo a avançar na definição de ações estratégicas que garantam não apenas maior eficiência e eficácia das políticas sociais, mas que estejam comprometidas, de fato, com a efetividade da transformação que se pretende implantar no País.

No Estado B a gestora estadual entrevistada ressaltou as capacitações e o assessoramento técnico-operacional, revelando uma visão mais ampliada sobre a gestão do Programa no Estado, destacando o processo de melhorias sociais e erradicação da pobreza e também que no cotidiano da gestão do Programa há atenção no uso de informações disponibilizadas pelo MDS e aperfeiçoamento constante do Programa. Esses dados revelam, para a burocrata, que há um processo de aprendizagem efetivo dos servidores estaduais e municipais. Afirmou, pois, que, aparentemente, existe uma boa compensação de informações sobre o Programa entre União, Estados e Municípios por meio do que classifica como "reaproveitamento dos estudos avaliativos realizados pelo MDS”, o que contribui, em alguma medida, para promover avanços nos processos de gestão do PBF. Embora tenha destacado uma avaliação positiva acerca do papel indutor das Políticas Avaliativas realizadas pelo MDS para o processo de aprendizagem da gestão local, a gestora apontou dificuldades internas da gestão estadual, especialmente na área de infraestrutura da secretaria estadual que comprometem o processo de aprendizagem esperado.

O Estado C pouco detalhou sobre o tema, mas corrobora os argumentos trazidos pelo Estado A em relação ao papel relevante da realização de seminários de monitoramento e avaliação junto aos estados e municípios, mas não explicou exatamente 
como ocorre o processo de aprendizagem por meio dessas ações. Com base na análise das respostas, pode-se inferir que a gestora defende que as informações advindas das pesquisas avaliativas do MDS sobre o PBF são utilizadas como balizadoras no processo de gestão estadual. Ela destacou como aspecto negativo ou dificuldade do processo de aprendizagem a morosidade na gestão e aplicabilidade dos recursos, embora não deixe claro quais as implicações trazidas pela morosidade das ações e projetos. Em síntese, a gestora sustentou, de forma simplista, sem fundamentar os argumentos, que os dados disponibilizados no banco de dados do MDS são utilizados como balizadores das políticas estaduais, de modo a contribuir para que a gestão estadual avance no atendimento das necessidades essenciais da população. O que se pode deduzir é que essas afirmações carecem de comprovação empírica para serem validadas como indutoras de processos de aprendizagem.

No Estado D a gestora destacou as dificuldades da secretaria para a gestão do PBF, ressaltando o déficit de servidores. Alegou que essa limitação de equipe técnica com competência complica o processo de divulgação e alcance dos resultados das pesquisas avaliativas produzidas e disponibilizadas pelo MDS, comprometendo, desse modo, a efetividade do Programa. Afirmou, pois, que faltam análises mais profundas e consequentes dos dados trazidos pelas pesquisas para que possam ser, de fato, indutoras de aprendizagem. Em outras palavras, a gestora chamou a atenção para o fato de que a realização de uma análise e/ou apreciações sobre as pesquisas é fundamental para melhorar a capacidade de gestão estadual do PBF, mas, infelizmente, esse esforço não tem sido feito. Um exemplo dessa crítica poderia ser refletida na seguinte reflexão: o que as informações disponibilizadas pelo MDS refletem/revelam sobre as práticas e desafios da política estadual para implantação e gestão do PBF? Ademais, a gestora apontou aspectos positivos sobre as pesquisas avaliativas do MDS para o $\mathrm{PBF}$, concordando no que diz respeito à contribuição desse esforço para a desmistificação de mitos e preconceitos sobre o Programa. Mas, se esse dado for considerado positivo para o processo de aprendizagem em gestão pública, é necessário aprofundar a discussão e introduzir o seguinte questionamento: ao contribuir para a desmistificação de mitos e preconceitos sobre o PBF, quais as aprendizagens percebidas pelos gestores e pela sociedade? Por fim, a gestora reafirmou o fato de que a realização de projetos de capacitação para gestores municipais do PBF seria um elemento indutor de aprendizagem, mas não esclareceu como esse processo ocorre atualmente.

O Estado E também demonstrou ausência de contingente técnico com domínio na atualização cadastral dos municípios e na convocação de setores locais para o acompanhamento do Programa. Mas essa conclusão não foi especificada, carecendo 
de argumentos que sustentem essa avaliação como fator limitador do processo de aprendizagem por meio dos resultados das avaliações realizadas pelo MDS. Outro aspecto apontado pela gestora como fator negativo para o processo de aprendizagem foi a realização de reuniões junto aos municípios, embora essa afirmação também careça de fundamentação, visto que apenas mencionou os "resultados insatisfatórios" das reuniões. As conclusões críticas apresentadas pela gestora sobre os problemas do processo de aprendizagem com base nas pesquisas avaliativas do MDS revelam uma contradição da entrevistada na medida em que destacou as melhorias operacionais ocorridas nos municípios, ressaltando que existe aprendizagem (especialmente mediante as ações de acompanhamento do PBF), mas não apresentou os critérios que fundamentam essa conclusão de modo a esclarecer como ocorre esse processo de aprendizagem e aperfeiçoamento da gestão do PBF no Estado.

\section{CONSIDERAÇÕES FINAIS}

Neste estudo buscou-se investigar se as pesquisas avaliativas implementadas pelo MDS para o PBF têm proporcionado o desenvolvimento de processos de aprendizagem nas práticas de gestão do Programa junto a governos estaduais. A partir da investigação junto a gestores estaduais foi possível destacar os seguintes pontos:

a) apenas dois gestores estaduais, entre os cinco, declararam promover ações que têm possibilitado processos de aprendizagem a partir dos resultados das avaliações realizadas pelo MDS, ações que, segundo destacaram, compreendem capacitações, assessoramento técnico-operacional e ações de monitoramento e avaliação nos municípios. Mas não deixaram de ressaltar que, muitas vezes, esse esforço foi limitado, visto que foi privilegiada apenas a divulgação dos resultados de algumas pesquisas entre as coordenações municipais, sem, contudo, ter sido estimulado um maior aprofundamento sobre os dados e informações disponibilizados;

b) em relação à utilização dos resultados das pesquisas avaliativas para o aperfeiçoamento do PBF nos estados, é notório observar a utilização limitada desses dados, confirmada pelas declarações feitas pelos gestores que apontaram que esses dados, mesmo que tenham potencial para ajudar no aperfeiçoamento das ações a serem planejadas, especialmente no que se refere às ações de monitoramento da gestão do Programa, ainda são 
vagos e suas apresentações resultam apenas na realização de seminários nos estados e reuniões com os municípios que apresentem índices insatisfatórios na gestão do Programa;

c) quando abordados sobre as principais conquistas alcançadas pelos processos avaliativos realizados pelo MDS para o PBF, predominam aspectos relacionados à gestão do CadÚnico, aos avanços e ao conhecimento sobre os impactos nos indicadores relacionados ao Programa e às suas condicionalidades e aos processos avaliativos realizados pelo MDS, destacando que esse esforço tem contribuído para a desmistificação de mitos e preconceitos acerca do Programa. Em síntese, não há registros (depoimentos) que reconheçam se, de fato, houve impacto ou avanços com base nos resultados das avaliações realizadas pelo Ministério no que se refere à contribuição efetiva para a correção de rotas (rumo) e/ou o aperfeiçoamento da gestão do Programa.

Com base nessas observações críticas, pode-se concluir que nos estados há pouca prática de compartilhamento, socialização e institucionalização do conhecimento, com base nas avaliações realizadas pelo MDS, o que limita, consideravelmente, qualquer esforço de aprendizagem organizacional dos estados por meio da utilização das avaliações.

Esses fatores limitadores podem estar relacionados ao conjunto de dificuldades elencadas pelos gestores estaduais, conforme destacado a seguir: o baixo contingente de servidores nas funções técnicas, especialmente para atender às demandas da gestão compartilhada entre estados e municípios; a ausência de política continuada de capacitação; a ausência de experiência com a utilização de banco de dados e análise de indicadores de avaliação; limitações da infraestrutura das secretarias estaduais; e déficit de servidores.

Esses fatores refletem na atuação eficaz dos burocratas e suas influências na produção de políticas públicas, principalmente as ações governamentais de promoção do bem-estar social, limitando, como apontam Lotta, Pires e Oliveira (2014), as funções da burocracia do Estado brasileiro nas dimensões interpessoal, informacional e decisória.

Pode-se inferir, conforme apontado na revisão teórica e por diversos autores como Guimarães et al. (2003), Bastos, Gondim e Loiola (2004) e Carmo e Oliveira (2009), que estão ausentes as condições e processos organizacionais que promovam e 
facilitem o processo de aprendizagem organizacional. Os dados trazidos pelos sujeitos pesquisados demonstram, portanto, que há pouca sinalização para o desenvolvimento de aprendizagem formal nos estados, o que significa deduzir que falta investimento em ações institucionalizadas, provenientes de mudanças organizacionais significativas que reflitam a introdução de diversos artefatos organizacionais inovadores, como estrutura, regras e procedimentos, junto às secretarias estaduais que as capacitem a utilizar os dados das pesquisas avaliativas para melhorar a gestão do Programa.

Tomando como base que o conceito de aprendizagem organizacional diz respeito a como os recursos organizacionais (pessoas, máquinas, dinheiro, conhecimentos, tecnologias, etc.) interagem com a finalidade de alterar atitudes, comportamentos e valores organizacionais, visando, assim, aperfeiçoar as ações da organização (GUIMARÃES et al., 2003), entende-se que a percepção dos gestores estaduais sobre esse aspecto é bastante crítica ao afirmarem que os recursos organizacionais existentes são limitados. Com base nessa percepção, pode-se deduzir que as limitações infraestruturais, organizacionais e administrativas estão minando as possibilidades de aprendizagem cumulativa a respeito das ações de avaliação.

Dessa maneira, reconhece-se que a avaliação é um instrumento que ajuda a organização a adquirir e desenvolver conhecimentos, porém, os resultados apontados pelos gestores estaduais pesquisados demonstram que as avaliações produzidas pelo MDS oferecem para os Estados poucos ensinamentos efetivos para a melhoria continuada da gestão do Programa. Essa conclusão contraria, portanto, as considerações feitas por Thoenig (2000), ao ressaltar que a avaliação pode atuar como uma ferramenta importante para o aprendizado, visto que os dados da pesquisa revelam que essa afirmativa é relativa, pois depende muito da concepção, aplicação e uso que se atribui a esse instrumento. Ao analisar as informações passadas pelos gestores estaduais pode-se concluir que os resultados das pesquisas avaliativas do MDS para o PBF não estão auxiliando os governos estaduais na geração de pontos de reflexão e discussão sobre o planejamento e gestão do Programa, especialmente no que se refere ao processo decisório.

\section{REFERÊNCIAS}

ARGYRIS, C.; SCHÖN, D. A. Organizational Learning II: theory, method, and practice. Boston: Addison-Wesley Publishing Campany, Inc., 1978. 
BASTOS, A. V. B.; GONDIM, S. M. G.; LOIOLA, E. Aprendizagem organizacional versus organiza que aprende: características e desafios que cercam estas duas abordagens de pesquisa. Revista de Administração da Universidade de São Paulo, v. 39, n. 3, p. 220-230, jul./set. 2004.

BOULLOSA, R. F. Contribuições conceituais e metodológicas para a avaliação de processos e práticas de gestão social a partir das perspectivas da Policy analysis e da abordagem social da aprendizagem. In: COLÓQUIO INTERNACIONAL SOBRE PODER LOCAL - DESENVOLVIMENTO E GESTÃO SOCIAL DE TERRITÓRIOS, 11., 2009, Salvador. Anais... Salvador, 2009.

BRASIL. Constituição. República Federativa do Brasil de 1988. Brasília, DF: Senado Federal, 1988.

CALMON, K. M. N. A avaliação de programas e a dinâmica da aprendizagem organizacional. PPP - Planejamento e Políticas Públicas, n. 19, p. 3-70, jun. 1999.

CARMO, M. I.; OLIVEIRA, A. R. Capacitação, socialização e institucionalização do conhecimento: uma análise do processo de aprendizagem organizacional em municípios. In: COLÓQUIO INTERNACIONAL SOBRE PODER LOCAL - DESENVOLVIMENTO E GESTÃO SOCIAL DE TERRITÓRIOS, 11., 2009, Salvador. Anais... Salvador, 2009.

DULCI, O, S. Estudo sobre as contribuições das pesquisas implementadas pela secretaria de avaliação e gestão da informação no campo da transferência de renda e de serviços socioassistenciais. Desenvolvimento social em debate: Síntese das pesquisas de avaliação de programas sociais do MDS: 2006-2010, Brasília, DF: MDS; SAGI, n. 13, dez. 2010.

ESCOLAR, C.; DOMENCH, P. Los Proyectos y Programas Sociales y la Evaluación. Reflexiones en Torno a una Experiencia. Políticas sociais - acompanhamento e análise IPEA, n. 5, p. 106-110, ago. 2002.

FARIA, C. A. P. A política da avaliação de políticas públicas. Revista Brasileira de Ciências Sociais, v. 20, n. 59, p. 97-109, out. 2005.

GUIMARÃES, T. A. et al. Explorando o construto organização de aprendizagem no setor público: uma análise em órgão do poder executivo federal brasileiro. O\&S, v. 10, n. 27, p. 111-125, maio/ago. 2003. 
IBGE. Síntese de indicadores sociais. Disponível em: <https://www.ibge.gov.br/ estatisticas-novoportal/sociais/protecao-social/9221-sintese-de-indicadores-sociais. html>. Acesso em: 20 jan. 2015.

LOTTA, G. S.; PIRES, R. R. C.; OLIVEIRA, V. E. Burocratas de médio escalão: novos olhares sobre velhos atores da produção de políticas públicas. Revista do Serviço Público, Brasília, DF: ENAP, v. 4, n. 65, p. 463-492, out./dez. 2014.

\section{MINISTÉRIO DO DESENVOLVIMENTO SOCIAL E COMBATE À FOME.} Programa Bolsa Família. Disponível em: <http://www.mds.gov.br/bolsafamilia> Acesso em: 10 jan. 2015.

MOZZATO, A. R.; GRZYBOVSKI, D. Análise de conteúdo como técnica de análise de dados qualitativos no campo da administração: potencial e desafios. Revista de Administração Contemporânea, v. 15, n. 4, p. 731-747, 2011.

NASCIMENTO, E. R. Gestão pública. São Paulo: Saraiva, 2006.

NOGUEIRA, R. A.; CAVALCANTE, P. L. Avaliação e monitoramento: duas experiências de institucionalização na gestão das políticas públicas no Poder Executivo Federal Brasileiro. In: CONGRESO INTERNACIONAL DEL CLAD SOBRE LA REFORMA DEL ESTADO Y DE LA ADMINISTRACIÓN PÚBLICA, SALVADOR DE BAHIA, 14., 2009, Salvador. Anais... Salvador, 2009.

RASHMAN, L.; WITHERS, E.; HARTLEY, J. Organizational learning and knowledge in public service organizations: A systematic review of the literature. International Journal of Management Reviews, v. 11, i. 4, p. 463-494, 2009.

SCHNEIDER, A. L. The Evolution of a Policy Orientation for Evaluation Research: A Guide to Practice. Public Administration Review, v. 46, i. 4, p. 356-363, 1986. SOARES NETO, A. Aprendizagem de auditores fiscais no contexto da prática profissional. 2010. 166 p. Dissertação (Mestrado em Administração)-Universidade Federal da Paraíba, João Pessoa, 2010.

THOENIG, J. C. A avaliação como conhecimento utilizável para reformas de gestão pública. Revista do Serviço Público, ano 51, n. 2, p. 54-71, abr./jun. 2000.

VAITSMAN, J.; RODRIGUES, R. W. S.; PAES-SOUSA, R. O Sistema de Avaliação e Monitoramento das Políticas e Programas Sociais: a experiência do Ministério do Desenvolvimento Social e Combate à Fome do Brasil. Série Policy Paper, Brasília, DF, n. 17, 2006. 
WEISS, C. H. Have we learned anything new about the use of evaluation? American Journal of Evaluation, ano 19, i. 1, p. 21-34, 1998.

\section{Como citar este artigo:}

\section{ABNT}

MONTEIRO, Doraliza Auxilidora Abranches; RIBEIRO, Elizabeth Matos. Avaliação de políticas públicas como indutora de aprendizagem: percepção de gestores estaduais do Programa Bolsa Família. RACE, Revista de Administração, Contabilidade e Economia, Joaçaba: Ed. Unoesc, p. 105-130, 2017. Edição Especial. Disponível em: <http://editora.unoesc.edu.br/index.php/race>. Acesso em: dia/mês/ano.

APA

Monteiro, D. A. A., \& Ribeiro, E. M. (2017). Avaliação de políticas públicas como indutora de aprendizagem: percepção de gestores estaduais do Programa Bolsa Família [E. especial]. RACE, Revista de Administração, Contabilidade e Economia, 105-130. Recuperado em dia/mês/ano, de http://editora.unoesc.edu.br/index.php/race 
